\title{
Perancangan Aplikasi Point Of Sales (POS) Berbasis Android (Studi Kasus: Warkop Vape Salatiga)
}

\author{
Restiawan Yoga Pratama ${ }^{1}$, Ramos Somya ${ }^{2}$ \\ ${ }^{1,2}$ Universitas Kristen Satya Wacana; Jl. Diponegoro 52-60, Salatiga 50711, Indonesia, Fax. \\ 321433 \\ ${ }^{3}$ Jurusan Teknik Informatika, FTI UKSW, Salatiga \\ Email:672016085@student.uksw.edu ${ }^{1}$,ramos.somya@uksw.edu ${ }^{2}$
}

\begin{abstract}
The purpose of this research was to help the transaction in Warkop Vape Salatiga. The stall was using traditional way. Traditional means that using conventional process from the financial record to product management, therefore a Point Of Sales application was made, so the stall's owner could work easier. This research used the spiral or Boehm method. In this method, there was a risk analysis that was useful for analyzing the risks that would arise from the needs and design which had been made in the previous stages. The design of this system used technology from firebase, which was the real-time database feature. It also utilized barcode and qr-code technology from the ZXing library. The result of this research is that the android based point of sales app could facilitate the transaction process going on at a Warkop Vape Salatiga. This could be seen from the system testing using the black box method which showed good results, all system functions were running well, apart from system testing, interviews with Warkop owners were also conducted. The stall owner convey that the application was easy to use and functions were in accordance with the needs of the store.
\end{abstract}

Keywords: point of sales, firebase, realtime database, barcode, qr-code

\begin{abstract}
Abstrak
Tujuan dari penelitian ini adalah untuk membantu proses transaksi yang terjadi di Warkop Vape Salatiga yang masih menggunakan cara tradisional. Maksud dari tradisional adalah menggunakan proses konvensional mulai dari pencatatan penjualan dan manajemen produk, maka dari itu dibuatlah aplikasi Point Of Sales untuk mempermudah pemilik warkop dalam bekerja. Penelitan ini menggunakan metode spiral atau Boehm. Pada metode ini terdapat risk analysis yang berguna untuk menganalisa resiko yang akan muncul dari kebutuhan dan desain yang sudah dibuat pada tahapan-tahapan sebelumnya. Perancangan sistem ini menggunakan teknologi dari firebase yaitu fitur realtime database dan juga memanfaatkan teknologi barcode dan qr-code dari library ZXing. Hasil dari penelitian ini adalah aplikasi Point Of Sales berbasis Android. Aplikasi Point Of Sales ini bisa mempermudah proses transaksi yang terjadi di Warkop Vape Salatiga. Hal ini bisa diketahui dari dilakukannya pengujian sistem dengan metode blackbox yang mendapatkan hasil bagus, semua fungsi sistem berjalan dengan baik, selain dengan pengujian sistem dilakukan juga wawancara dengan pemilik Warkop, pemilik Warkop mengatakan aplikasi mudah untuk digunakan dan fungsi sudah sesuai dengan kebutuhan toko.
\end{abstract}

Kata kunci: point of sales, firebase, realtime database, barcode, qr-code 


\section{PENDAHULUAN}

Perkembangan teknologi yang pesat membuat penyampaian informasi menjadi mudah dan cepat. Penyampaian informasi merupakan hal yang penting dan berpengaruh. Penyampaian informasi yang baik dan cepat dapat meningkatkan produktifitas, baik dalam memperoleh, mengolah dan menggunakan informasi secara akurat [1]. Berkembangnya teknologi dengan pesat, membuat informasi bisa diakses dengan mudah melalui perangkat mobile atau yang lebih sering disebut smartphone. Perangkat mobile atau smartphone sendiri sudah menjadi kebutuhan pokok. Salah satunya penggunaan smartphone dalam proses transaksi jual beli.

Pada masa sekarang sudah banyak toko yang menggunakan aplikasi kasir digital untuk mempermudah dalam melakukan proses transaksi. Meskipun begitu tetap masih ada toko yang melakukan proses transaksi secara tradisional, contohnya adalah Warkop Vape Salatiga, toko ini menjual berbagai produk rokok elektrik, selain itu toko ini masih melakukan proses transaksi dengan cara tradisional, maksud dari tradisional adalah, masih menggunakan buku sebagai pencatatan penjualan. Proses transaksi seperti ini sudah membantu, tetapi dalam penggunaannya sering terjadi kesalahan yang fatal, seperti kesalahan saat memasukkan data penjualan dan kesalahan saat menghitung total barang yang dijual. Proses penjualan secara konvensional juga memakan banyak waktu dan harus teliti dalam mengolah data laporan penjualan guna mengurangi kesalahan. Meskipun pencatatan penjualan dilakukan saat itu juga tetap saja saat dicatat di laporan penjualan harus dihitung dari awal.

POS (Point Of Sale) adalah sebuah sistem didunia bisnis yang penggunaannya menggunakan perangkat lunak dan perangkat keras yang saling terhubung satu sama lain untuk memudahkan proses transaksi. Proses transaksi bisa dikatakan selesai ketika sudah dititik penjualan (check-out) yang dilakukan di kasir. Kemudian sistem akan menghitung total pembelian [2]. Setelah harga sudah dihitung semua, pembayaran bisa dilakukan. Penggunaan Point of Sales (POS) bisa mengefisiankan waktu dan setiap catatan penjualan disimpan secara Realtime menggunakan Firebase, apabila terjadi kesalahan bisa diselesaikan pada saat itu juga.

Berdasarkan latar masalah tersebut, melalui penelitian ini akan dibuat aplikasi Point of Sales (POS) berbasis mobile Android dengan menggunakan database realtime Firebase, SQLite, library zxing untuk memindai Barcode dan QR code. Aplikasi Point of Sales (POS) berbasis Android ini diharapkan bisa mengatasi masalah yang ada. Batasan masalah penelitian ini adalah aplikasi yang berupa aplikasi Android, aplikasi ini hanya bisa diakses di Warkop Vape Salatiga.

\section{METODE PENELITIAN}

\subsection{Kajian Pustaka}

\subsubsection{Penelitian Terdahulu}

Terdapat beberapa penelitian yang pernah dilakukan tentang Point Of Sales, salah satunya adalah penelitian yang pernah dilakukan dengan judul "Rancang Bangun Aplikasi Android POS (Point Of Sale) Kafe untuk Kasir Portable dan Bluetooth Printer. aplikasi kasir portable yang membantu proses transaksi penjualan dibeberapa kafe yang belum memiliki sistem penjualan digital dimana saat melakukan rekapitulasi pendapatan hasil penjualan dan pembelian masih dilakukan dengan menggunakan aplikasi Microsoft Excel yang dilakukan dengan cara mengisi form khusus yang berisi daftar makanan dan minuman kemudian mengisikan daftar pesanan kedalam form yang kemudian dijadikan alat untuk merekap data transaksi dan bukti penjualan untuk pembeli. Perekapan data transaksi dilakukan setelah kafe sudah tutup yang kemudian 
memasukkan semua bukti penjualan. Setelah semua data transaksi dimasukkan bisa diketahui berapa dan apa saja barang terjual secara realtime, hal tersebut bisa terjadi karena sudah memiliki tatanan bentuk sendiri untuk pendataan tersebut. Namun pemilik toko masih kesulitan karena harus mendata satu persatu setiap hari dalam bentuk file excel. Hal tersebut lah yang mengilhami dibuatnya aplikasi ini untuk mempermudah dalam proses transaksi dan melakukan rekapitulasi laporan transaksi kafe dengan lebih tepat, cepat dan jelas" [3].

Pada penelitian yang lain yang berjudul Perancangan Aplikasi Point Of Sales Berbasis Desktop di Zone Cafe Purwokerto. "Sistem penjualan yang saat ini berjalan di Zone Café Purwokerto, Sering meningkatnyanya proses transaksi yang terjadi, untuk menanggulangi hal tersebut dibuat aplikasi Point Of Sales berdasarkan sistem transaksi yang sudah ada. Pengolahan data pegawai, makanan, transaksi, pemberian hak akses admin, pemberian hak akses kasir serta sistem keamanan kata sandi yang bekerja dengan baik dan lancar, sistem keamanan pada aplikasi dan basis data dilengkapi dengan kata sandi login yang dibatasi sebanyak 3 kali kesalahan. Aplikasi Point Of Sales ini memiliki spesifikasi rancangan input berupa dokumen biling order yang beguna untuk mendata pesanan pelanggan dan daftar menu produk yang berguna untuk melihat menu makanan dan minuman. Adapun spesifikasi data yang dihasilkan aplikasi ini berupa nota pembayaran yang berguna sebagai bukti telah membayar, laporan stok barang, laporan transaksi dan data penjualan" [4].

Penelitian selanjutnya yang pernah dilakukan memiliki judul Rancang Bangun Aplikasi Point Of Sales Distro Management System dengan menggunakan Framework React Native. "Perkembangan fashion remaja mengalami peningkatan yang menarik dan inovatif. Perkembangan fashion remaja yang semakin pesat dengan bertambahnya permintaan konsumen. Proses bisnis yang berjalan di distro ini masih menggunakan proses konvensional tanpa pemanfaatan teknologi saat ini, sehingga mereka mengalami kesulitan saat melakukan pencatatan transaksi dan manajemen produk. Berdasarkan masalah tersebut, maka dibuatlah aplikasi Point Of Sales untuk mempermudah pekerja distro dalam bekerja. Metode penelitian yang digunakan adalah metode classic life cycle, untuk pengumpulan dayang dengan cara melakukan wawancara, observasi, dan dokumentasi pada distro tempat melakukan penelitian. Hasil dari wawancara dan observasi maka dibuat rancangan sistem, rancangan basis data, dan rancangan user interface. Kemudian semua rancangan tadi dibuat aplikasi dengan framework React Native dan setelah aplikasi jadi kemudian dilakukan pengujian sistem terhadap aplikasi tersebut menggunakan metode Black Box testing. Hasil pengujian sistem pada aplikasi Point Of Sales ini sudah sesuai dengan yang diharapkan oleh pihak distro" [5].

Berdasarkan penelitian-penelitian yang berkaitan dengan POS (Point Of sale), guna pengembangan penelitian, maka dilakukan penelitian tentang Perancangan Aplikasi POS (Point Of Sale) berbasis Android di Warkop Vape Salatiga guna mempermudah pengguna dalam melakukan proses transaksi. Penelitian ini diharapkan bisa memberi kemudahan pengguna di Warkop Vape Salatiga dalam melakukan proses penjualan. Adapun teknologi yang digunakan adalah dengan menggunakan library Zxing untuk memindai barang menggunakan barcode maupun QR code, selain itu untuk perekapan data penjualan dan pendataan lainnya disimpan di Firebase dengan begitu bisa dilakukan secara langsung dan akurat. Basis data yang digunakan tidak hanya menggunakan Firebase, digunakan juga SQLite yang digunakan pada saat proses transaksi berlangsung.

\subsubsection{Android}

Android adalah sistem operasi yang berbasis linux yang diperuntukan perangkat mobile. Sistem operasi ini milik Google Inc bersama dengan 34 perusahaan lainnya yang bertujuan untuk mengembangkan sistem operasi ini, android sendiri menjadi sistem operasi yang sangat populer saat ini mengalahkan sistem operasi lain. Android menyediakan platform terbuka untuk penggunanya agar bisa mengembangkan aplikasi mereka sendiri [6]. Android adalah sistem

Pratama, et., al [Perancangan Aplikasi Point Of Sales (POS) Berbasis Android(Studi Kasus: Warkop Vape Salatiga)] 
opreasi yang tidak membedakan antara aplikasi inti dengan aplikasi pihak ketiga, android merupakan platform terbuka sehingga memudahkan para pengembang untuk membuat aplikasi $[7]$.

\subsubsection{Java}

Java merupakan bahasa pemrograman yang bisa dijalankan pada berbagai perangkat. Bahasa pemrogramman ini dibuat oleh James Gosling saat masih menjadi anggota Sun Microsystems yang saat ini lebih dikenal dengan nama Oracle, java sendiri dirilis pada tahun 1995, bahasa ini mengadopsi dari bahasa $\mathrm{C}$ dan bahasa $\mathrm{C}++$ namun dengan model objek yang lebih sederhana. Aplikasi-aplikasi yang berbasis java pada umumnya dikompilasi dalam $p$-code (bytecode) dan bisa dijalankan pada berbagai Java Virtual Machine (JVM) [8].

\subsubsection{Firebase}

Firebase adalah platform basis data milik Google Inc yang terhubung dengan cloud dan disimpan sebagai JSON dan disinkronkan secara langsung kepada klien yang terhubung dengan internet. Dalam Firebase memiliki fitur database realtime dimana setiap klien bisa berbagi informasi secara langsung apabila terhubung dengan internet. Realtime database adalah basis data yang tidak menggunakan $S Q L$, sehingga memiliki optimalisasi dan fungsionalitas yang berbeda dengan basis data SQL. API Realtime Database dibuat agar operasi yang lakukan berjalan dengan cepat [9]. Firebase adalah platform untuk aplikasi realtime, ketika data berubah maka aplikasi yang terhubung akan secara langsung melakukan perubahan secara langsung terhadap setiap perangkat yang dipakai, baik website maupun mobile [10].

\subsubsection{SQLite}

SQLite adalah suatu library yang menerapkan mesin database self-contained, serverless, zero-configuration, dan transactional. Self-contained berarti SQLite tidak membutuhkan terlalu banyak library eksternal atau dari sistem operasi. Serverless berati SQLite dalam mengakses database baik itu read atau write dapat secara langsung dari file database tanpa melalui proses server dan tidak mendukung pengaksesan secara remote (artinya database SQLite bisa dikendalikan dari jarak jauh dengan adanya jaringan computer, baik melalui jaringan lokal (intranet atau internet), dimana kebanyakan mesin SQL database diterapkan sebagai proses server yang terpisah[11].

\subsubsection{Zxing.Net}

Zxing.Net adalah port dari java yang bertujuan untuk membaca barcode dengan library ini barcode yang digunakan adalah image/bitmap. ZXing. Net dapat membaca image barcode dalam banyak format. Format seperti UPC-A, UPC-E, EAN-8, EAN-13, Code 39, Code 93, Code 128, ITF, Codabar, MSI, RSS-14 (semua variasi), QR Code, Data Matrix, Aztec dan PDF-417. ZXing.Net dapat membaca image barcode ini dengan menganalisa dan mengenali berdasarkan pattern yangterdapatdalam libraryini. Prosesnya panjang dan bisa dilihat sourcecode-nya [12].

\subsection{7. $Q R$ code}

Quick Respone code (QR code) adalah teknik mengubah data tertulis menjadi kode 2 dimensi yang tercetak pada media yang lebih ringkas. $Q R$ code merupakan barcode 2 dimensi yang pertama kali dipakai oleh perusahaan Jepang Denso Wave pada tahun 1994. Kode ini pertama kali digunakan untuk mempermudah pendataan suku cadang kendaraan dan berkembang dengan digunakan pada berbagai bidang [13]. 


\subsection{Metode penelitian}

Metode yang digunakan untuk penelitian ini adalah metode Spiral atau model Boehm, metode ini adalah metode yang mengambil model Prototyping dengan metode pengulangannya dan juga mengambil metode Waterfall menggunakan pengendalian dan sistematikanya [14]. Metode ini diharapkan bisa menghasilkan produk tertentu selama pengerjaan penelitian ini. Metode ini terdapat risk analysis yang berguna untuk menganalisa resiko yang akan muncul dari kebutuhan dan desain yang sudah dibuat pada proses sebelumnya. Tahapan pengerjaan penelitian yang digunakan pada perancangan aplikasi POS (Point Of Sale) berbasis android bisa dilihat pada Gambar 1.

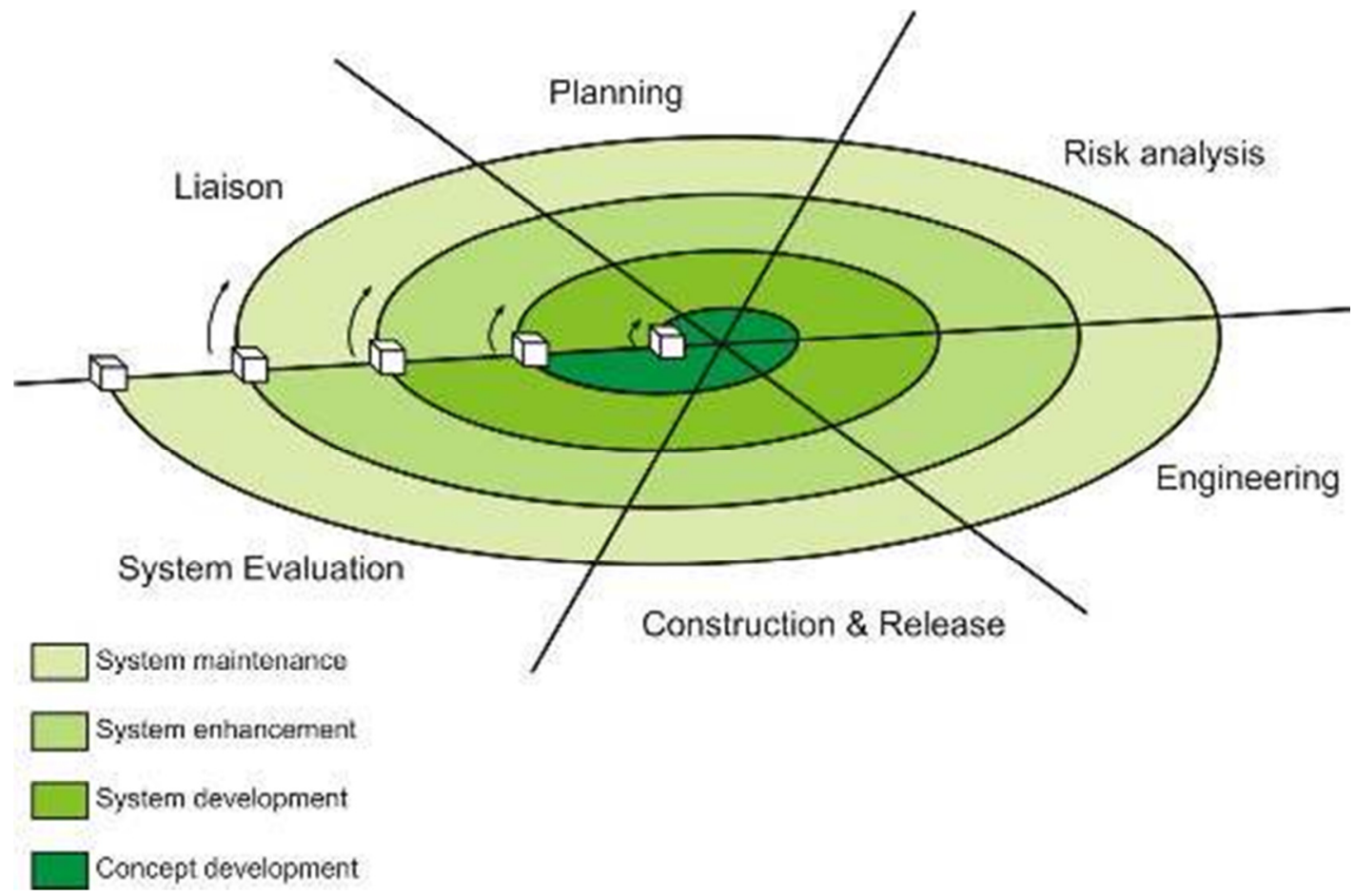

Gambar 1. Metode Penelitian Spiral Atau Boehm [15]

Tahapan penelitian pada Gambar 1, adalah sebagai berikut:

1. Tahap Liaison. Pada tahap ini melakukan diskusi dengan pemilik Warkop Vape untuk mengetahui kebutuhan apa saja yang diperlukan pada aplikasi POS Warkop Vape.

2. Tahap Planning. Pada tahap ini menerjemahkan kebutuhan user kedalam bentuk desain user interface aplikasi POS Warkop Vape. Pada tahap ini juga dilakukan perencanaan pembuatan aplikasi, mulai dari berapa lama pengerjaan berlangsung dan sumber daya apa saja yang dibutuhkan.

3. Tahap Risk Analysis. Setelah perencanaan sudah dibuat selanjutkan akan dilakukan analisa resiko dan kendala apa saja yang didapat setelah membuat desain aplikasi sebelum dilakukan proses selanjutnya. Pada tahap ini juga dibuat prototype dari aplikasi untuk dicoba dan mengetahui kekurangannya.

4. Tahap Engineering. Pada fase atau tahap ini prototype pada tahab sebelumnya dikembangkan dengan menambahkan dan memperbaiki kekurangan yang didapat dari tahap sebelumnya.

5. Tahap Construction \& Release. Pada tahap ini aplikasi siap diujicoba, disini pengujian dilakukan dengan metode blackbox dan juga wawancara langsung kepada pemilik toko. Setelah pengujian selesai dilakukan aplikasi siap digunakan. 
6. Tahap System Evaluation. Pada tahap ini pemilik toko melakukan evaluasi terhadap aplikasi dan memberi feedback. Jika dirasa kurang maka akan dilakukan perbaikan pada aplikasi hingga didapatkan hasil yang diinginkan.

\subsubsection{Use Case Diagram}

Use Case Diagram merupakan diagram yang mendeskripsikan sebuah interaksi antara aktor dengan sistem yang dibuat. Use Case juga digunakan untuk mengetahui fungsi apa saja yang ada.

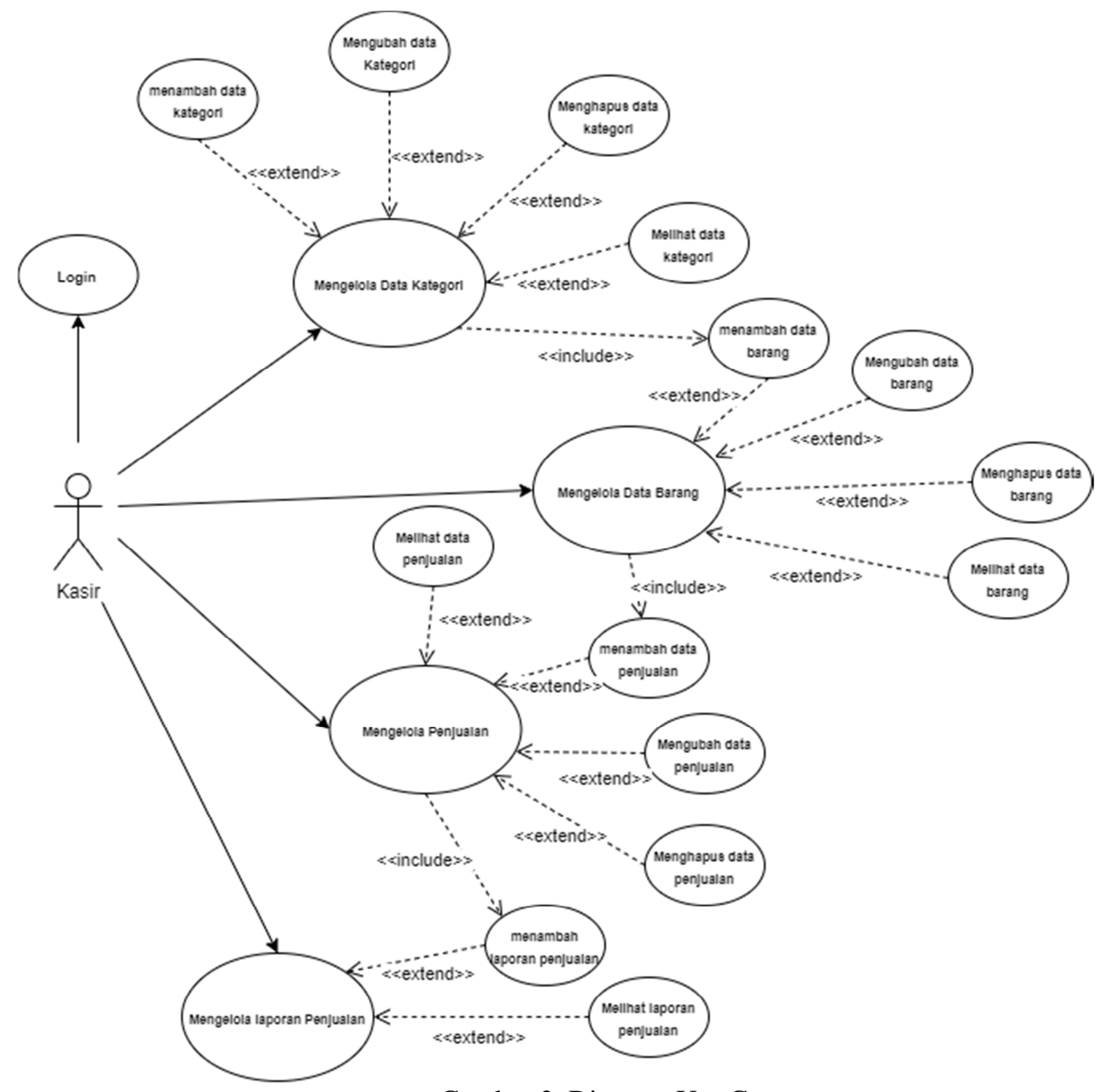

Gambar 2. Diagram Use Case

Pada Gambar 2 diagram use case ini terdapat satu aktor, aktor tersebut adalah kasir yang berperan sebagai pengelola sistem informasi seperti mengelola data penjualan yang berisikan barang-barang yang akan dijual. Aktor kasir juga mengelola data kategori barang, data barang dan laporan penjualan. 


\subsubsection{Activity Diagram}

Activity Diagram adalah rancangan sistem yang akan dijalankan. Activity Diagram juga digunakan untuk mendefinisikan alur tampilan dari sistem.

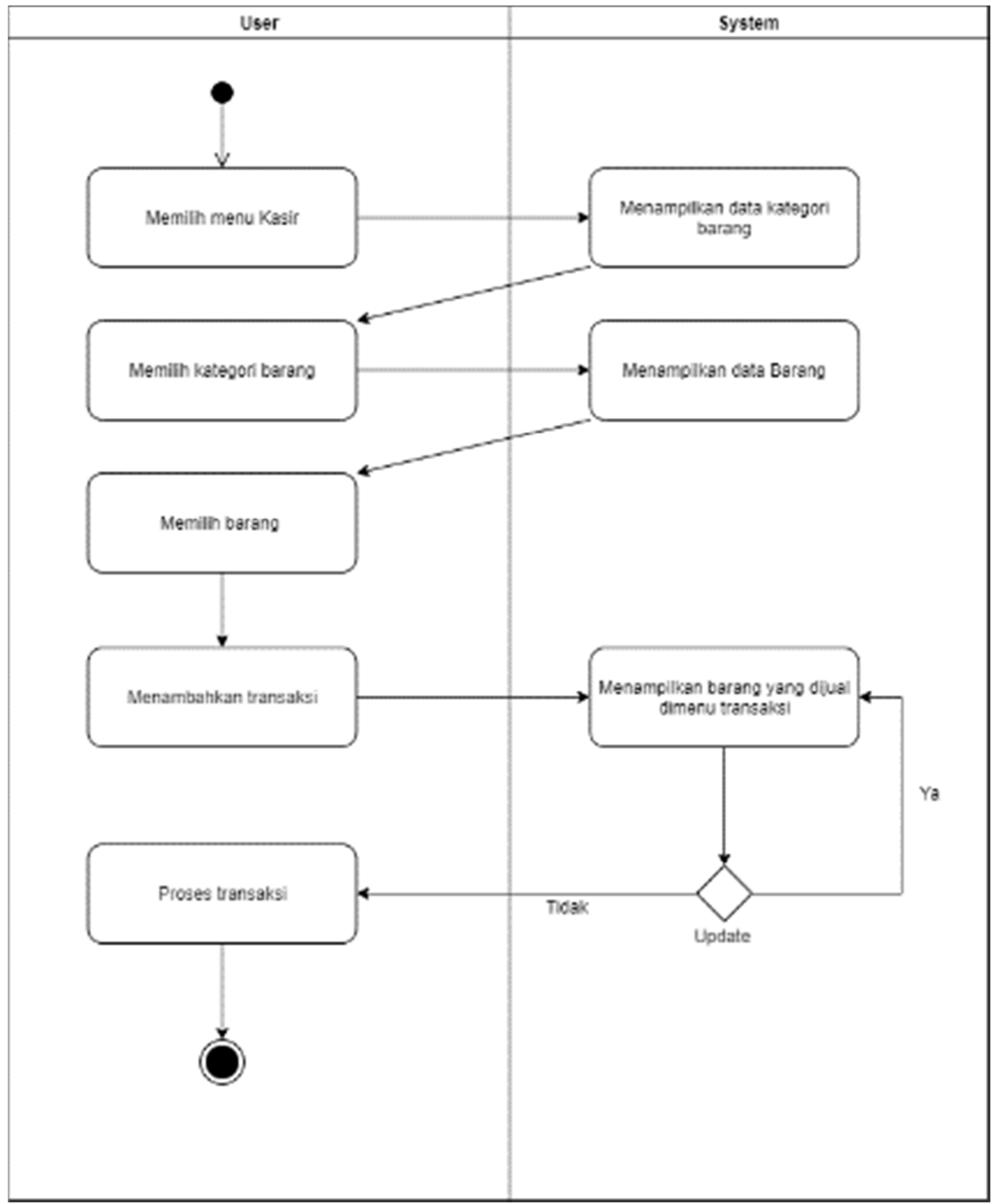

Gambar 3. Activity Diagram Pemesanan

Pada Gambar 3 dapat dijelaskan, user memilih menu kasir untuk melakukan proses penjualan, maka akan muncul tampilan kategori barang. Setelah itu user memilih kategori barang kemudian akan muncul barang-barang yang ada dikategori tersebut. Kemudian user memilih barang dan memasukkan kedalam menu transaksi. Setalah itu didalam menu transaksi akan ditampilkan barang yang dipilih tadi, didalam menu transaksi bisa dilakukan update untuk 
menambahkan jumlah barang yang dijual. Apabila tidak tidak dilakukan update maka transaksi bisa langsung diselesaikan.

\subsubsection{Sequence Diagram}

Sequence Diagram merupakan diagram yang menggambarkan antara object dan juga class. Kegunaannya untuk menunjukkan rangkaian interaksi antara object.

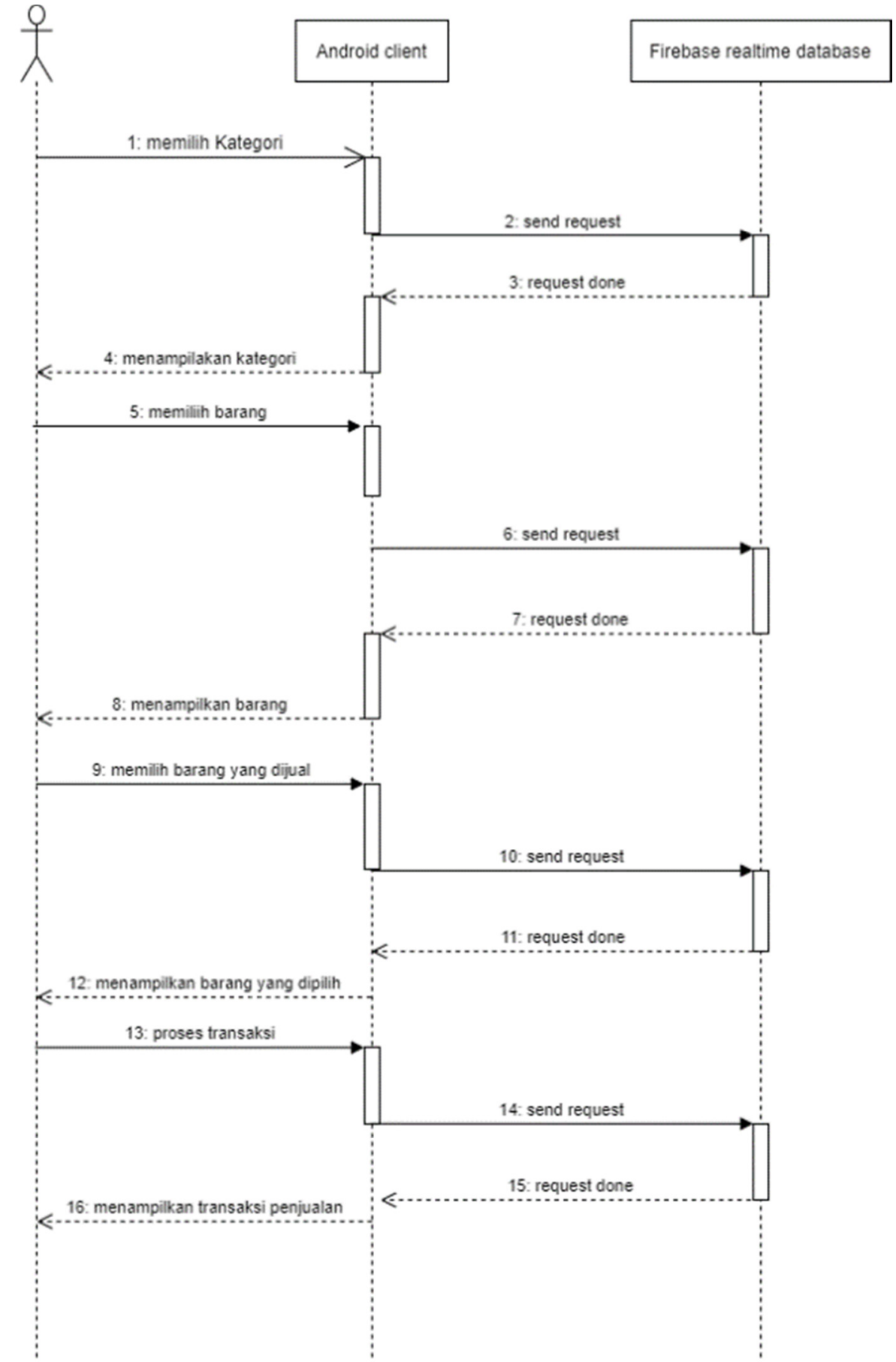

Gambar 4. Sequence Diagram Pemesanan 
Pada Gambar 4, menunjukkan proses transaksi yang terjadi. Sequence diagram sendiri berguna untuk memberikan gambaran kegunaan dan fungsi dari use case. Proses ini diawali dengan melakukan request ke database, kemudian data yang dipilih akan ditampilkan.

\subsubsection{Arsitektur Sistem}

Arsistektur sistem adalah sebuah model yang menggambarkan struktur suatu sistem. Arsitektur system ini bertujuan agar struktur yang dirancang dapat menjawab kebutuhan pengguna.

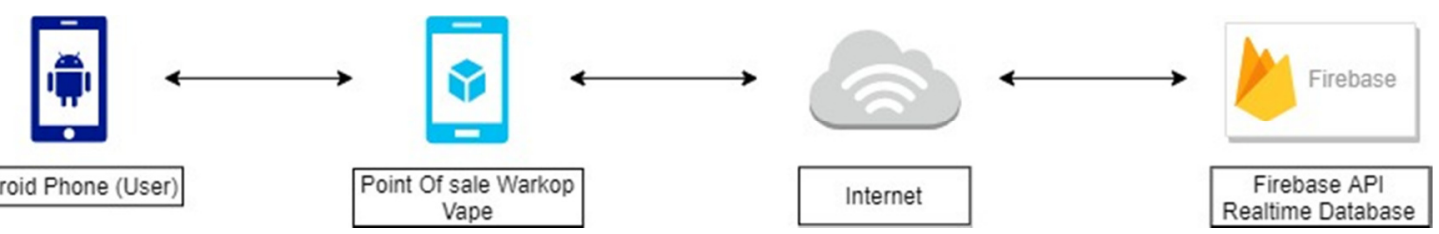

Gambar 5. Arsitektur Sistem

Pada Gambar 5 menunjukan perancangan arsitektur dari aplikasi POS Warkop Vape, arsitektur ini bertujuan untuk memudahkan memahami alur kerja dari aplikasi POS Warkop Vape. Ketika user mengakses aplikasi ini maka smartphone user harus terhubung dengan jaringan internet, sehingga bisa mengakses data yang tersimpan pada Firebase Realtime Database.

\section{HASIL DAN PEMBAHASAN}

Setelah semua tahapan dilakukan, berhasil dibuat sebuah aplikasi Point of Sale berbasis Android. Aplikasi ini menggunakna dua Database yaitu Firebase yang berbasis Cloud Database sebagai basis data utamanya dan SQLite yang berbasis SQL Server, tetapi penggunakan SQLite sangat terbatas, SQLite hanya digunakan pada saat proses transaksi sebagai penyimpanan sementara data barang yang dipilih, dimana nantinya barang yang dipilih akan dikirim Firebase.

\subsection{Implementasi}

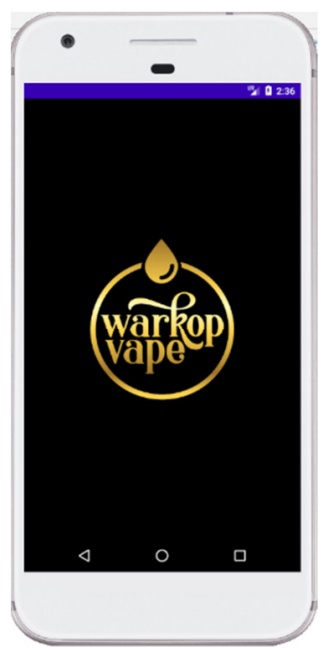

Gambar 6. Tampilan Halaman Splash 
Gambar 6 adalah halaman splash, halaman ini akan muncul saat aplikasi dijalanakan. Halaman ini bertujuan untuk memberi tahu identitas dari aplikasi ini.

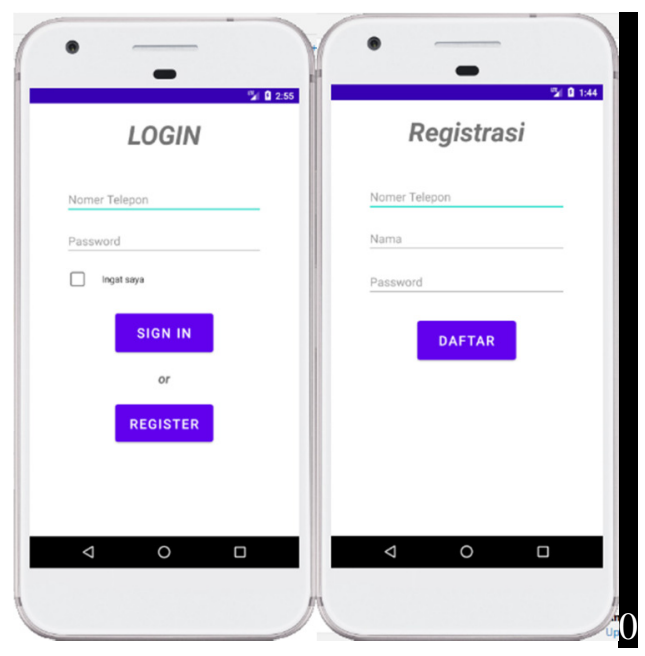

(a)

(b)

Gambar 7. Tampilan Halaman Login (a) dan Registrasi (b)

Gambar 7 (a) adalah halaman login, Setalah tampilan splash selesai, pada saat user pertama kali membuka aplikasi akan ditampilkan halaman login. User diwajibkan mengisi nomer telepon dan kata sandi untuk bisa mengakses halaman selanjutnya. Gambar 7 (b) adalah halaman registrasi, apabila ingin menambah karyawan, karyawan baru tersebut bisa melakukan registrasi, sehingga bisa mengakses aplikasi ini.

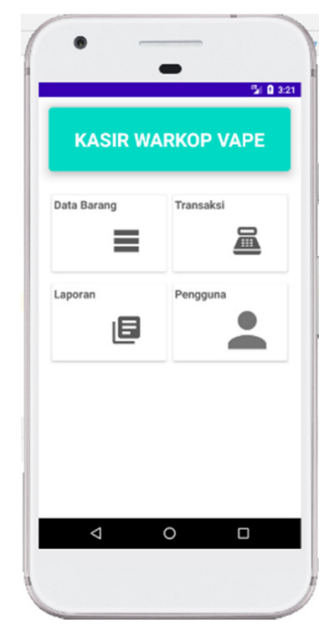

Gambar 8. Tampilan Halaman Dashboard

Gambar 8 adalah halaman dashboard. Halaman ini berisi cardview yang bisa mengakses keseluruh aplikasi ini, pertama pada bagian kiri atas ada menu data barang, menu ini berguna untuk mengakses data semua barang yang dijual. Kedua ada menu transaksi pada bagian kanan atas, semua transaksi dilakukan di menu ini. Ketiga adalah menu laporan yang berada pada bagian kiri bawah, di menu ini semua data penjualan dicatat. Keempat atau yang terakhir yaitu 
menu pengguna yang terletak pada bagian kanan bawah, menu ini bertujuan untuk menyimpan data pengguna dan pengguna bisa melakukan log out pada menu ini.

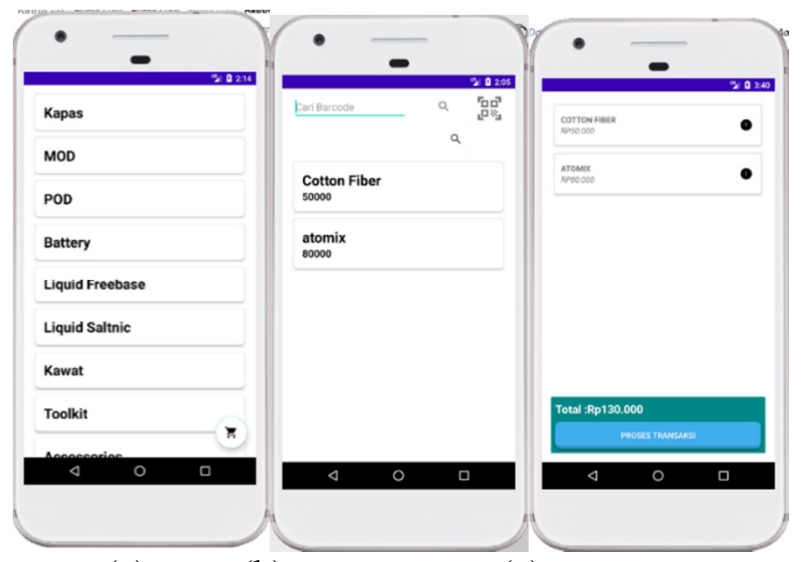

(a)

(b)

(c)

Gambar 9. Tampilan Halaman Transaksi

Gambar 9 (a) adalah halaman transaksi untuk memilih kateogri barang yang dibeli, pada halaman ini ditampilkan semua kategori dari barang yang dijual, sehingga memudahkan pengguna untuk menentukan barang apa yang akan dibeli. Gambar 9 (b) adalah halaman dari barang sesuai dari kategori yang dipilih, pada halaman ini terdapat dua search bar, search bar pertama digunakan untuk mencari barang dengan qrcode atau barcode menggunakan library Zxing. Searchbar kedua digunakan untuk mencari barang berdasarkan nama barang tersebut menggunakan library materialSearchBar. Dua searchbar ini digunakan karena firebase tidak memperbolehkan ada dua OrderBy dalam satu method, selain itu data barang pada perlengkapan vape tidak semua menggunakan barcode dan qrcode. Gambar 9 (c) adalah halaman utama transaksi, pada halaman ini menggunakan basisdata sqlite sebagai media penyimpanannya dan basis data ini digunakan secara offline atau hanya disimpan pada smartphone android pengguna, sqlite hanya digunakan untuk penyimpanan sementara sebelum diproses untuk dikirim ke firebase. 


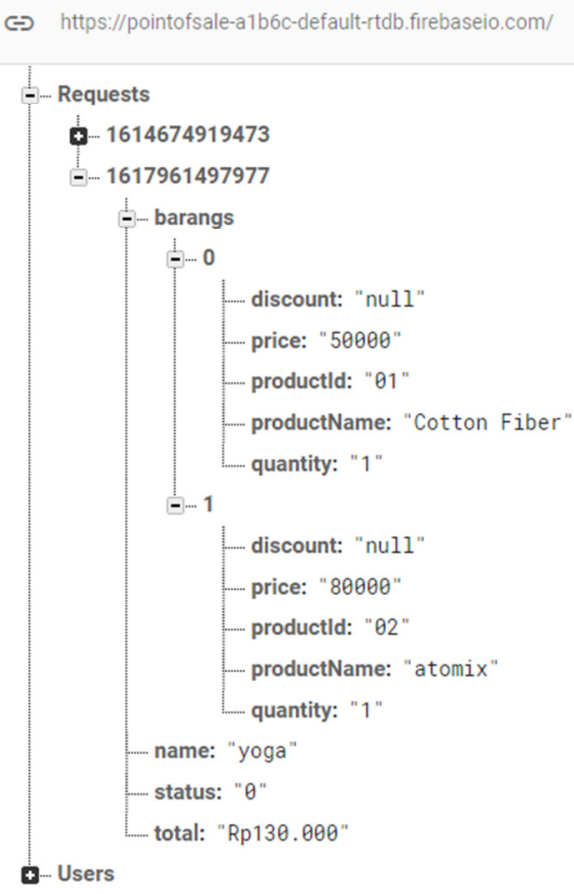

Database location: United States (us-central1)

Gambar 10. Tampilan Database Firebase

Gambar 10 adalah tampilan dari database firebase, Firebase Realtime Database ini bukan merupakan SQL(structured query language) melainkan menggunakan JSON(JavaScript Object Notation). Halaman ini menampilkan data penjualan mulai dari barang yang dijual, jumlah beli, kasir yang melayani, dan juga total bayar. Untuk data barangnya sendiri diambil dari database sqlite yang tersimpan di-smartphone yang sudah di-instal aplikasi ini.

\subsection{Kode Program}

Tabel 1. Kode Program Menampilkan isi keranjang dan total bayar

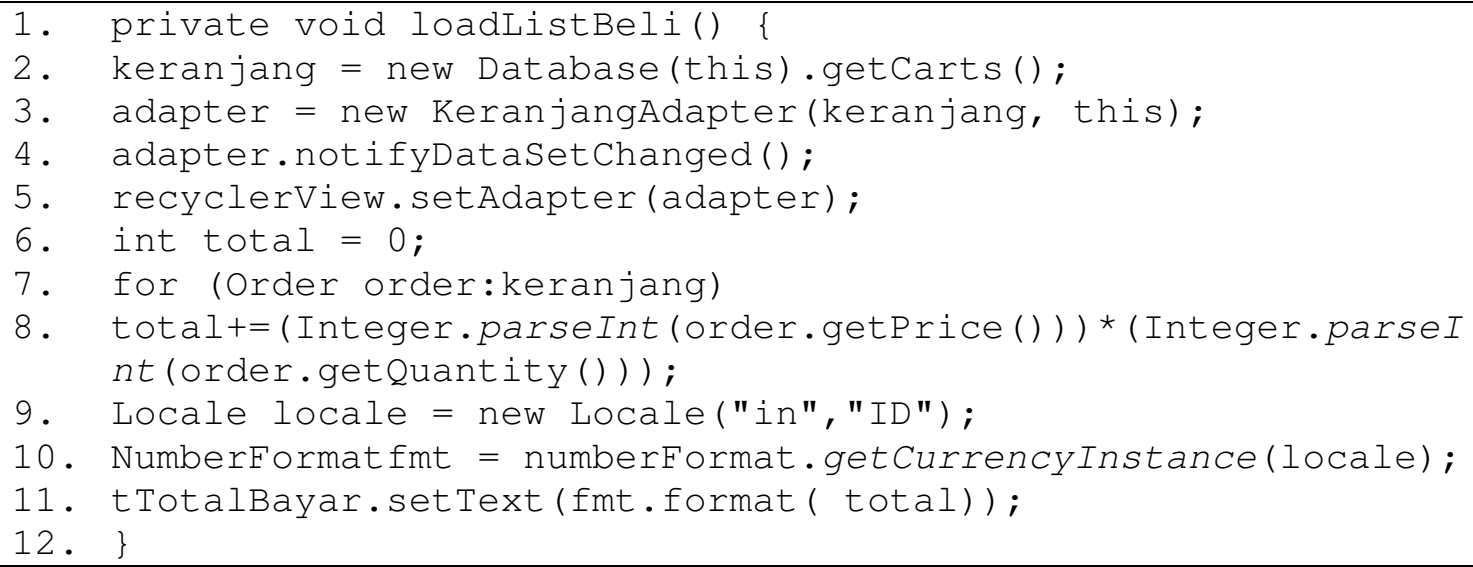


Tabel 1 adalahKode Program yang berfungsi untuk menampilkan isi keranjang dan total bayar, dimana nantinya jika tombol proses bayar diklik akan data akan langsung dikirim firebase dari sqlite. Jumlah total bayar bisa diketahui dari for pada line 7 dan 9 total didapat dari harga ditambah jumlah barang yang dibeli yang kemudian total bayar ditulis ditotal bayar, kemudian untuk mata uang yang digunakan adalah rupiah, hal tersebut bisa dilihat pada kode program pada line 9 dan 10. Total bayar akan ditampilkan dengan kode program pada line 12 .

Tabel 2. Kode Program Menampilkan Rekap Barang Terjual

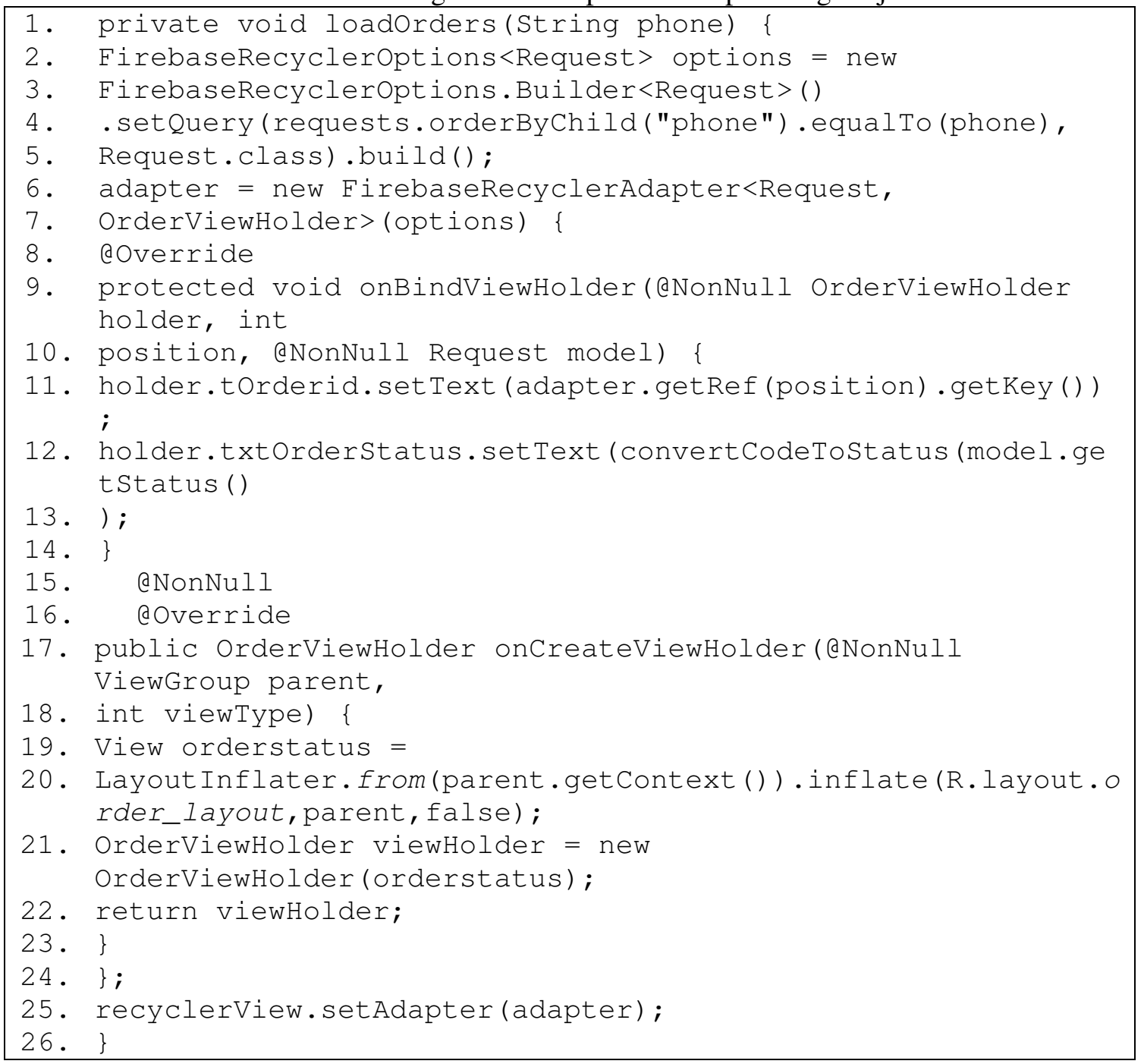

Kode Program 2 ini berfungsi untuk menampilkan rekap data penjualan, semua data penjualan akan ditampilkan di sini, dengan cara melakukan request ke firebase bisa dilihat pada line 2 dimana saat akan membuka halaman ini sistem melakukan request terlebih dahulu ke firebase. Pada line 22 terdapat viewHolder untuk orderstatus, maksudnya adalah data barang yang sudah terjual masih bisa dirubah lagi, tetapi hal ini hanya bisa dilakukan apabila status order belum final. 


\subsection{Pengujian Sistem}

Pengujian sistem dilakukan untuk mengetahui apakah sistem sudah berjalan dengan baik atau belum. Pengujian sistem yang dilakukan pada aplikasi ini adalah testing Alpha dan testing Beta. Testing Alpha dilakukan dengan metode Black Box, poin-poin pengujian bisa dilihat pada Tabel 1

Tabel 1. Pengujian Alpha Aplikasi Point of Sale Berbasis Android

\begin{tabular}{|c|c|c|c|c|c|}
\hline No. & $\begin{array}{c}\text { Modul } \\
\text { Pengujian }\end{array}$ & Data Input & $\begin{array}{c}\text { Data } \\
\text { output }\end{array}$ & Hasil Pengujian & Status \\
\hline 1 & Login & $\begin{array}{l}\text { Nomer Telepon } \\
\text { dan Password }\end{array}$ & - & Berhasil login & Valid \\
\hline 2 & $\begin{array}{l}\text { Menambah } \\
\text { data barang }\end{array}$ & $\begin{array}{l}\text { Nama barang, } \\
\text { Deskripsi } \\
\text { barang, Harga, } \\
\text { Barcode barang }\end{array}$ & $\begin{array}{l}\text { Tertambah } \\
\text { ke firebase }\end{array}$ & $\begin{array}{l}\text { Berhasil menambahkan } \\
\text { Barang dan terinput } \\
\text { pada table barang }\end{array}$ & Valid \\
\hline 3 & $\begin{array}{l}\text { Melakukan } \\
\text { scan barcode } \\
\text { dan grcode }\end{array}$ & $\begin{array}{l}\text { Gambar barcode } \\
\text { atau qrcode }\end{array}$ & $\begin{array}{l}\text { Barang } \\
\text { berhasil } \\
\text { ditemukan }\end{array}$ & $\begin{array}{l}\text { Berhasil menemukan } \\
\text { barang }\end{array}$ & Valid \\
\hline 4 & $\begin{array}{l}\text { Mencari } \\
\text { barang } \\
\text { berdasarkan } \\
\text { nama } \\
\end{array}$ & Nama Barang & $\begin{array}{l}\text { Barang } \\
\text { Berhasil } \\
\text { ditemukan }\end{array}$ & $\begin{array}{l}\text { Berhasil menemukan } \\
\text { barang }\end{array}$ & Valid \\
\hline 5 & $\begin{array}{l}\text { Menambahka } \\
\mathrm{n} \text { barang } \\
\text { untuk dijual }\end{array}$ & $\begin{array}{l}\text { Data barang, } \\
\text { jumlah beli }\end{array}$ & $\begin{array}{l}\text { Tertambah } \\
\text { ke sqlite } \\
\text { database }\end{array}$ & $\begin{array}{l}\text { Berhasil menambahkan } \\
\text { data barang, jumlah beli } \\
\text { dan total bayar }\end{array}$ & Valid \\
\hline 6 & $\begin{array}{l}\text { Melakukan } \\
\text { transaksi }\end{array}$ & $\begin{array}{l}\text { data barang, } \\
\text { jumlah beli dan } \\
\text { total bayar }\end{array}$ & $\begin{array}{l}\text { Data } \\
\text { pindah dari } \\
\text { sqlite } \\
\text { database ke } \\
\text { firebase }\end{array}$ & $\begin{array}{l}\text { Aplikasi menampilkan } \\
\text { data penjualan }\end{array}$ & Valid \\
\hline
\end{tabular}

Berdasarkan pada pengujian sistem pada Tabel 1, didapatkan hasil bahwa sistem yang telah di uji dapat berjalan dengan baik. Kemudian Setelah aplikasi jadi maka aplikasi ini selanjutnya akan dilakukan beta testing kepada pemilik Warkop Vape Salatiga. Beta testing ini dilakukan dengan cara melakukan wawancara langsung kepada pemilik toko dan masa percobaan penggunaan selama 3 hari.

Berdasarkan wawancara dengan pemilik Warkop dan percobaan selama 3 hari. Selama masa percobaan, aplikasi tidak terdapat masalah apapun dan bisa berjalan dengan baik. Pemilik warkop menyampaikan bahwa sistem yang dibangun sudah sesuai dengan yang dibutuhkan. Pemilik Warkop menyampaikan bahwa aplikasi mudah digunakan dan semua fungsi atau fitur sudah sesuai dengan kebutuhan, selain itu pemilik Warkop juga memberikan masukan tentang tampilan yang masih sederhana.

\section{KESIMPULAN}

Berdasarkan hasil penelitian dan pengujian sistem yang dilakukan bisa disimpulkan bahwa aplikasi sudah sesuai dengan kebutuhan. Hal ini bisa dilihat dari hasil pengujian sistem, sistem yang di uji dapat berjalan dengan baik, selain dengan pengujian sistem, dilakukan juga 
wawancara dengan pemilik Warkop dan pengujian penggunaan aplikasi selama 3 hari. Wawancara yang dilakukan dengan pemilik Warkop mendapat hasil yang positif, pemilik warkop menyampaikan aplikasi sudah sesuai dengan kebutuhan, salah satu contohnya adalah saat melakukan proses transaksi, proses ini bisa dilakukan dengan cepat, mudah dan tepat. Selama masa percobaan penggunaan aplikasi tidak ditemukan masalah apapun.

\section{SARAN}

Adapun saran yang diberikan adalah pada bagian user interface-nya, sehingga kedepannya bisa dikembangkan lagi agar user bisa lebih nyaman saat menggunakan aplikasi ini.

\section{UCAPAN TERIMA KASIH}

Penulis mengucapkan terima kasih kepada kedua orang tua yang telah memberi support, pemilik Warkop Vape Salatiga yang sudah memperbolehkan melakukan penelitian di Warkop Vape Salatiga, serta Bapak Ramos Somya, S. Kom., M. Cs. Selaku dosen pembimbing yang memberi bimbingan kepada penulis sampai akhir.

\section{DAFTAR PUSTAKA}

[1] S. C. Cahyodi dan R. W. Arifin, 2017. "Sistem Informasi Point of Sales Berbasis Web pada Colony Amaranta Bekasi,” Inf. Syst. Educ. Prof., Vol. 1, No. 2, hal. 189-204,

[2] S. Kosasi, 2015, "Perancangan Aplikasi Point of Sale Dengan Arsitektur Client/Server Berbasis Linux dan Windows," Creat. Inf. Technol. J., Vol. 1, No. 2, hal. 116, doi: 10.24076/citec.2014v1i2.15.

[3] G. Pamungkas dan H. Yuliansyah, 2017, "Rancang Bangun Aplikasi Android Pos (Point of Sale) Kafe Untuk Kasir Portable dan Bluetooth Printer," JST (Jurnal Sains dan Teknol., Vol. 6, No. 1, hal. 199-208, doi: 10.23887/jst-undiksha.v6i1.8828.

[4] P. Pramono dan H. M. Nur, 2013. "Perancangan Aplikasi Point of Sales Berbasis Desktop (Studi Kasus : Zone Cafe Purwokerto)," hal. 214-219,

[5] P. D. A. Wiguna, I. P. A. Swastika, dan I. P. Satwika, 2019, "Rancang Bangun Aplikasi Point of Sales Distro Management System Dengan Menggunakan Framework React Native," J. Nas. Teknol. dan Sist. Inf., Vol. 4, No. 3, hal. 149-159, doi: 10.25077/teknosi.v4i3.2018.149-159.

[6] S. Surahman dan E. B. Setiawan, 2017, "Aplikasi Mobile Driver Online Berbasis Android Untuk Perusahaan Rental Kendaraan,” J. Ultim. InfoSys, Vol. 8, No. 1, hal. 3542, doi: 10.31937/si.v8i1.554.

[7] N. K. Ceryna Dewi, I. B. G. Anandita, K. J. Atmaja, dan P. W. Aditama, 2018, "Rancang Bangun Aplikasi Mobile Siska Berbasis Android,” SINTECH (Science Inf. Technol. J., Vol. 1, No. 2, hal. 100-107, doi: 10.31598/sintechjournal.v2i1.291. 
[8] Barri, 2015 "Perancangan Aplikasi Sms Gateway Untuk Pembuatan Kartu Perpustakaan Di Fakultas Teknik Unsrat,” J. Tek. Elektro dan Komput., Vol. 4, No. 1, hal. 23-28,.

[9] Karindra, 2017. "Belajar Realtime Database pada Firebase Android," https://medium.com/@namakulinux/belajar-realtime-database-pada-firebase-android9e016f9aa60f (diakses Nov 27, 2019).

[10] E. A. W. Sanad, 2019, "Pemanfaatan Realtime Database di Platform Firebase pada Aplikasi E-Tourism Kabupaten Nabire,” J. Penelit. Enj., Vol. 22, No. 1, hal. 20-26, doi: 10.25042/jpe.052018.04.

[11] D. A. N. Presentasi, A. Setiyadi, dan T. Harihayati, 2015 "Penerapan Sqlite pada Aplikasi Pengaturan Waktu Ujian dan Presentasi,” Vol. 13, No. 2, hal. 221-226,

[12] A. Wijaya dan A. Gunawan, 2016, "Penggunaan $Q R$ Code Sarana Penyampaian Promosi dan Informasi Kebun Binatang Berbasis Android,” J. Bianglala Inform., Vol. 4, No. 1, hal. 16-21, doi: 10.31294/bi.v4i1.586.

[13] J. Dedy irawan dan E. Adriantantri, 2019, "Pemanfaatan Qr-Code Segabai Media Promosi Toko,” J. Mnemon., Vol. 1, No. 2, hal. 56-61, doi: 10.36040/mnemonic.v1i2.39.

[14] Ani Binti Fitriah, 2016. "Sistem Informasi Penggajian Pegawai Menggunakan Metode Spiral pada SMK Intensif Baitussalam Tanjunganom Nganjuk,” hal. 1-10,

[15] A. N. Utomo dan M. Alfaridzi, 2018. "Perancangan Sistem Informasi pada Percetakan CV Citra Kencana Jakarta Timur Berbasis Web,” J. Rekayasa Inf., Vol. 7, No. 1, hal. 43-47, 